\title{
Modeling salmon lice effects on sea trout population dynamics using an individual-based approach
}

\author{
R. D. Hedger ${ }^{1, *}$, O. H. Diserud ${ }^{1}$, B. Finstad ${ }^{1,2}$, A. J. Jensen ${ }^{1}$, D. K. Hendrichsen ${ }^{1}$, \\ O. Ugedal ${ }^{1}$, T. F. Naesje ${ }^{1}$
}

${ }^{1}$ Norwegian Institute for Nature Research (NINA), PO Box 5685 Torgarden, 7485 Trondheim, Norway ${ }^{2}$ Department of Biology, Norwegian University of Science and Technology (NTNU), 7491 Trondheim, Norway

\begin{abstract}
Salmon lice Lepeophtheirus salmonis infestation of sea trout Salmo trutta results in both additional marine mortality and behavioral changes which may contribute to sea trout population decline. For effective management of activities that increase exposure to salmon lice, such as salmon aquaculture, it is necessary to have a full understanding of how salmon lice may affect sea trout populations. An individual-based model (IBTRUTTA) was therefore developed to investigate the potential effects of salmon lice infestation on sea trout population abundance and dynamics based on data from the River Halselva and Altafjord system in northern Norway. This model allowed investigation of the effect of lice-induced mortality and also the compensatory salmonid behavioral mechanisms of premature return to freshwater, either persistent for overwintering or transitory after which sea trout could go back to sea. It was found that, in the absence of compensatory mechanisms, even low rates of lice infestation could lead to marked declines in sea trout abundance. Compensatory behavioral mechanisms had the potential to reduce these declines, but persistent premature return resulted in reduced body mass of returning adults. The shape of the stock-recruitment relationship was also shown to strongly affect how lice-induced mortality impacted the population.
\end{abstract}

KEY WORDS: Individual-based model - Sea trout - Salmon lice - Lice-induced mortality · Premature return

\section{INTRODUCTION}

The salmon louse Lepeophtheirus salmonis is a marine parasite of salmonid fishes such as sea trout Salmo trutta L., Atlantic salmon Salmo salar L., and Arctic char Salvelinus alpinus L. Salmon lice infestation may cause host mortality by decreasing osmoregulatory ability, damaging tissue (in turn, increasing susceptibility to secondary infection from viruses and bacteria), and/or changing host behavior (see Finstad \& Bjørn 2011, Thorstad et al. 2015). Established mortality thresholds vary among studies: a review by Wagner et al. (2008) showed morbidity (ill

${ }^{*}$ Corresponding author: richard.hedger@nina.no health) beginning to occur at $>1$ lice $\mathrm{g}^{-1}$ host fish in contrast, Taranger et al. (2015) suggested 100\% expected mortality or compromised reproduction at $>0.1$ lice $\mathrm{g}^{-1}$ host in veteran $(>150 \mathrm{~g})$ sea trout and Arctic char. Salmon lice are adapted to saltwater and die if the host swims into freshwater, so high salmon lice infestations may lead to behavioral responses in the fish with premature (early) return to freshwater, where the fish may remain until the following year, or short-term ephemeral movement to freshwater or brackish habitats for delousing (Birkeland 1996, Birkeland \& Jakobsen 1997, Halttunen et al. 2018, Serra-Llinares et al. 2018).

() The authors 2021. Open Access under Creative Commons by Attribution Licence. Use, distribution and reproduction are unrestricted. Authors and original publication must be credited. 
The concentration of salmonid hosts in fish farms can act as a major point source of salmon lice (Heuch \& Mo 2001, Vollset et al. 2018b) that may infest wild salmonids. Salmonid farming has increased the presence of salmon lice since the 1980s (Tully et al. 1993, Finstad \& Bjørn 2011, Thorstad \& Finstad 2018) such that salmon lice infestation has become a pertinent issue. Effects may be particularly significant among sea trout because they remain in areas with high lice infestation pressure for extended periods (Thorstad et al. 2015). Taranger et al. (2015) concluded that salmon lice posed a moderate-to-high mortality threat for wild sea trout in 67 out of 109 Norwegian sites examined. The Norwegian government has ratified a regulatory framework dividing the Norwegian coastline into 13 independent 'production zones' where the governing principle for management decisions within each zone will be based on environmental sustainability (Vollset et al. 2018a). This management system ('the traffic light system') is based on scientific advice in peer-reviewed articles (Taranger et al. 2015) and national reports (Taranger et al. 2013, Karlsen et al. 2016) and uses the effect of salmon lice on wild salmonid populations as a sustainability indicator.

To properly inform management strategies, it is essential to have robust information on how lice infestation may affect salmonid populations in general and sea trout populations in particular. Empirical studies conducted in situ or in controlled environments may provide information on lice infestation effects, but are limited in scope as they typically examine only specific aspects of the infestation and often ignore long-term effects on the host population. In contrast, dynamic population models that can quantify direct and indirect effects of lice infestation levels on host population size and composition may provide important information on how lice infestation affects salmonid populations and be suitable for informing management decisions. In the present study, we simulate the effect of salmon lice infestations on a sea trout population using an individualbased modeling approach. We investigate how lice infestations may affect sea trout population size and composition via lice-induced mortality, and liceinduced premature return to freshwater (either persistent, where sea trout remain in freshwater until the following year, or transitory, where sea trout return to sea immediately on delousing).

We investigate potential effects of sea lice on the sea trout population of the Halselva and Altafjord system. This system is situated within the Norwegian subarctic $\left(70^{\circ} 2^{\prime} \mathrm{N}, 22^{\circ} 57^{\prime} \mathrm{E}\right)$ and consists of a small river (Halselva, $20 \mathrm{~km}$ long) that discharges into a large fjord (Altafjord). The study area was chosen because it had a well-maintained monitoring program of both the sea trout population and salmon lice infestation levels. Permanent fish traps have been in place across the river $200 \mathrm{~m}$ upstream from the sea for over $25 \mathrm{yr}$, which have captured all migrating fish larger than $10 \mathrm{~cm}$ in length. Annual sea trout smolt production from the river was $1100 \pm 665$ (mean \pm SD) individuals between 1988 and 2012 (maximum = 2675) (Jensen et al. 2016). Sea trout use the Altafjord during summer before returning to the Halselva for overwintering. The outer part of the fjord contains several fish farms (Skarðhamar et al. 2018), which act as a source of salmon lice. Lice infestation on sea trout in the fjord increases across the summer from a prevalence of $<10 \%$ with few lice per host in Weeks 25-28 of the calendar year to a prevalence $>90 \%$ and a median and maximum infestation of 5 and 90 lice per host in Week 31-32 (Bjørn \& Finstad 2002, Nilsen et al. 2018).

\section{METHODS}

Description of the model, IBTRUTTA, follows the Overview, Design concepts and Details (ODD) protocol (Grimm et al. 2020). This model was written in $\mathrm{R}$ version 3.6.3 (R Development Core Team 2020).

\subsection{Purposes and patterns}

The model IBTRUTTA is an individual-based population model, formulated to simulate the effect of salmon lice on sea trout population abundance and dynamics, with the purpose of integrating existing knowledge into a decision-making framework (specifically, the Norwegian lice 'traffic light' system), increasing the understanding of system properties, and identifying where knowledge gaps exist. The model was designed to examine the potential for lice-induced premature return of sea trout to freshwater (either persistent or transitory) to mitigate effects of salmon lice on population abundance, alongside the potential for stock-recruitment processes in freshwater to influence the effect of salmon lice on population abundance.

The model was formulated on the hypothesis that there would be reduced impacts of lice infestation on population abundance when there was (1) premature return to freshwater and (2) a stock-recruitment curve where density-dependent effects on recruitment occured over a restricted range of stock sizes. 


\subsection{Entities, state variables, and scales}

The model is composed of 2 spatial entities: a freshwater habitat (e.g. a river) and a marine habitat (e.g. a fjord), that individual sea trout can migrate between. Sea trout are modeled as individual entities from the post-smolt stage onwards.

Each individual sea trout is characterized by state variables (Table 1), which govern processes applied to it. The life-stage variable characterizes the individual's ontogeny and has the potential values of: (1) post-smolt (a sea trout that has migrated to sea for the first time, created from an egg-to-smolt stock-recruitment curve); (2) adult returner (a sea trout that has returned to freshwater after a summer at sea); or (3) veteran (an adult returner that has migrated back to sea after overwintering in freshwater). All variables other than sex are dynamic.

The model is non-spatial, but contains 2 compartments separately representing the freshwater and marine environments. The temporal extent is user controlled (e.g. $100 \mathrm{yr}$ ). The model time-step is $1 \mathrm{wk}$. Population structure (population abundance per lifestage and age group) is updated weekly. Model functions are applied on a weekly basis with the exception of certain freshwater processes-stockrecruitment, overwinter body mass decrease and overwinter mortality which are applied on an annual basis.

\subsection{Process overview and scheduling}

Processes modeled by submodels are stock-recruitment and smolt production, migration between river and sea, background mortality, body mass change, and lice infestation and lice effects. Fig. 1 cross-references submodel descriptions in the submodel section (Section 2.7).

\subsubsection{Egg deposition, stock-} recruitment, and smolt production

Each adult returning female individual is assigned a probability of spawning. If it spawns, it produces eggs as a function of its body mass. Smolt production is then calculated from egg deposition using a stock-recruitment curve. Smolt production from a given spawning cohort is assigned an age distribution which determines the subsequent years in the simulation when the postsmolt individuals are generated.

Table 1. State variables of sea trout individuals

\begin{tabular}{|ll|}
\hline Variable & Type: options \\
\hline Age & Integer: years \\
Sex & Nominal: male, female \\
Body mass & Continuous (g) \\
Life stage & Nominal: post-smolt, adult re- \\
& turner, veteran \\
Location & Nominal: freshwater, marine \\
Number of summers & \\
experienced from first & \\
migration to sea & Integer: years \\
Number of winters & \\
experienced from first & \\
return to freshwater & Integer: years \\
Number of chalimus lice & Ordinal \\
Number of preadult/ & \\
adult lice & Ordinal \\
\hline
\end{tabular}

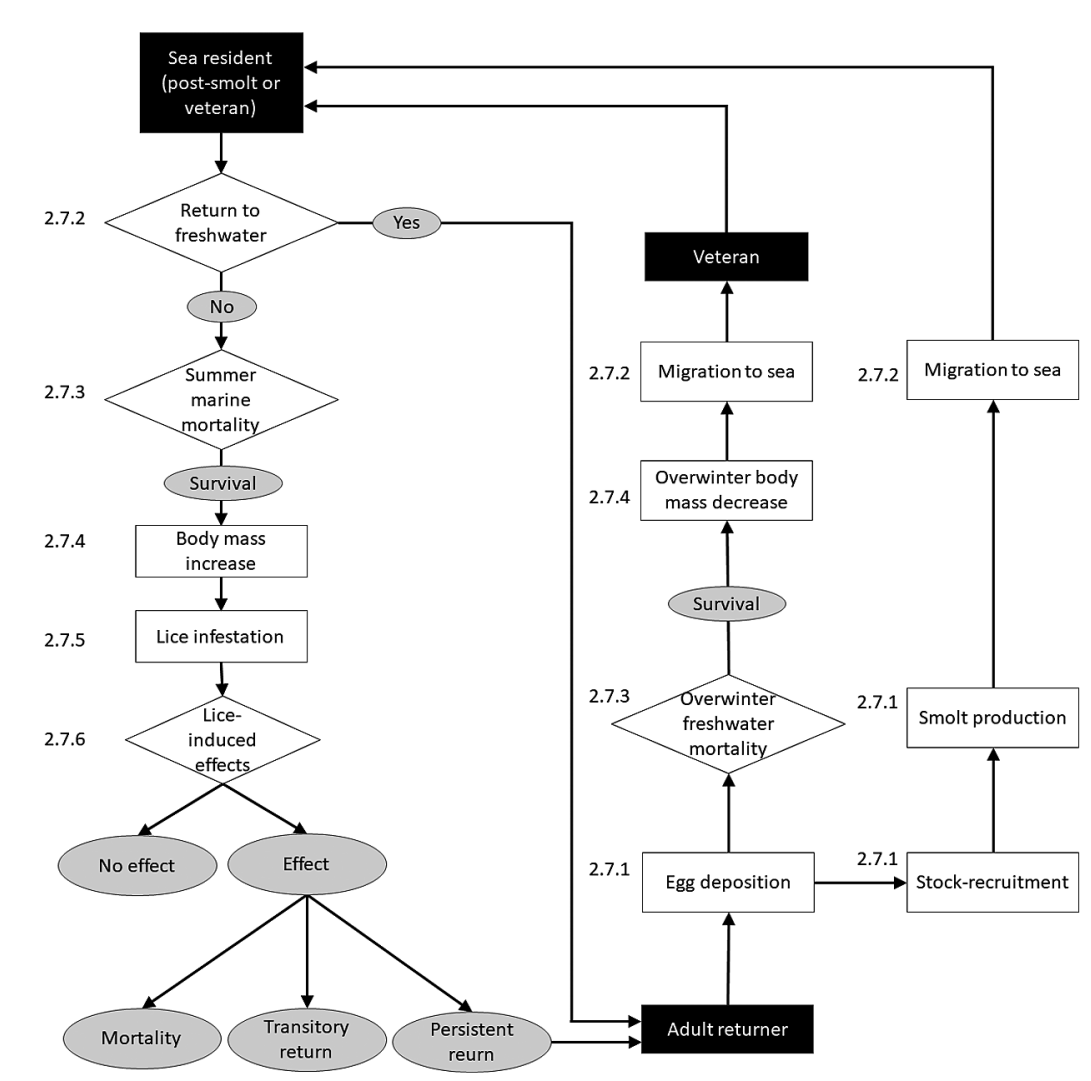

Fig. 1. IBTRUTTA individual-based model configuration. Numbers beside each function refer to submodel descriptions in the corresponding sections of text 


\subsubsection{Migration between freshwater and sea}

Post-smolt individuals (first-time migrants to sea) are generated each time-step from yearly smolt production as a function of week of the year; this is parameterized to increase to a probability of 1 throughout the year. Veteran individuals in freshwater (those that have previously migrated to sea, and overwintered in freshwater) also experience a weekly probability of returning to sea that increases throughout the year to 1. Each time-step, a sea trout individual at sea experiences a probability of returning to freshwater as a function of the number of weeks the individual has been at sea that year.

\subsubsection{Background mortality}

Background mortality is applied both in the sea and in freshwater. Each time-step, an individual at sea experiences a marine mortality probability dependent on how many summers at sea the individual (post-smolt or veteran) has experienced. If the individual survives to return to freshwater, it experiences an annual overwinter freshwater mortality.

\subsubsection{Body mass change}

Each individual at sea experiences a body mass increase each time-step, dependent on the body mass in the previous time-step. Individuals that have returned to freshwater experience an overwinter body mass decrease. It is necessary to model body mass at the weekly time-step when at sea because body mass affects the lice-induced effects. Body mass change in freshwater is modeled as 1 overwinter step because we are only interested in how this affects veteran body mass the following year.

\subsubsection{Lice infestation}

The state variables, number of chalimus lice, and number of preadult/adult lice are updated on individuals at sea each time-step. The number of additional chalimus lice for each individual at each time-step is derived from a probability distribution representing infestation pressure. Chalimus lice are converted to the preadult/adult lice stage $2 \mathrm{wk}$ after infestation, representing ontogenetic development of the louse on the sea trout.

\subsubsection{Lice-induced effects}

Individuals at sea that are infested by salmon lice are subject to mortality or show delousing behavior (persistent or transitory return to freshwater) as a function of the number of preadult/adult lice per gram of host body mass.

\subsection{Design concepts}

\subsubsection{Basic principles}

The life cycle of sea trout is represented in the model through reproduction, ontogeny, body mass change, migration, and mortality relationships that have been well described in the literature (Thorstad et al. 2016). The model addresses in particular how sea trout population abundance and dynamics are dependent on lice infestation, and how sea trout mortality from lice infestation may be influenced by an adaptive response to infestation where there is persistent or transitory return to freshwater (Thorstad et al. 2016). Additionally, the model addresses how abundance and dynamics are influenced by the form of the stock-recruitment relationship in freshwater, given that stock-recruitment may play a regulatory role (see Lorenzen 2008). This is an ongoing priority for research (ICES 2018). Current knowledge gaps can be addressed through process modeling because it allows for a more complete overview of system behavior, rather than relying on occasional pointsamples (which is the norm for field-based studies).

\subsubsection{Emergence}

Population abundances and dynamics emerge from characteristics of the sea trout individuals, such as when they migrate to sea and return to freshwater, their lice infestation intensity per gram of body mass, and the type of effect that lice infestation initiates (mortality, persistent return, or transitory return).

\subsubsection{Adaptation}

Premature return to freshwater (either persistent, where the sea trout individual remains until the following year, or transitory, where the sea trout individual returns to sea the following week) is modeled as an adaptive response to lice infestation on the host individual. The type of adaptive behavior (probabil- 
ity of persistent or transitory return) is externally controlled. Individuals are assumed to perfectly sense the intensity of preadult/adult lice attached to them ( $\mathrm{N}$ preadult/adult lice $\mathrm{g}^{-1}$ host body mass). Individuals do not, however, have modeled objectives, learning, or prediction.

\subsubsection{Interaction}

Interaction between sea trout individuals is not modeled as there is no strong evidence to suggest this will impact on population dynamics within the marine environment. The non-linear aspect of the stock-recruitment relationship assumes an interaction: a lower ratio of smolt production to egg deposition at higher egg depositions due to competition between juvenile sea trout. The aggregate effect of this is implicit in the stock-recruitment relationship.

\subsubsection{Stochasticity}

No stochasticity is used in initial conditions. Submodels are partly stochastic. Sea trout individuals die, migrate, or spawn if a pseudorandomly generated number exceeds a threshold predicted by a deterministic function.

\subsubsection{Collectives}

The model does not include collectives.

\subsubsection{Observation}

The model outputs data on the sea trout population structure and lice infestation levels as commaseparated files for subsequent analysis (we used R version 3.6.3). Observations are recorded at the population level. For each week of the simulation, this includes information on lice prevalence (percentage of the sea trout population infected), lice intensity (mean number of lice per host), and abundance of sea trout per life stage, per age group and location, alongside information on the numbers of sea trout that have returned prematurely. For each year of the simulation, this includes information on egg deposition, smolt production, and number of adult returners.

Sea trout populations are simulated for a userspecified number of years. The first years are used as a 'burn-in' period to create stable population processes (see Williams et al. 2017), and model outputs from these years are discarded. Effects of model conditions on sea trout population dynamics are determined from modeled outputs over the remaining years. For all simulations in the current study, we simulate the sea trout population for $150 \mathrm{yr}$; the first $50 \mathrm{yr}$ are used as a burn-in time, and the observations from the remaining $100 \mathrm{yr}$ are used to investigate the effect of model conditions on the sea trout population.

\subsection{Initialization}

The model is initialized with a user-specified smolt production, and run for a user-specified number of years.

\subsection{Input data}

The model does not utilize environmental data.

\subsection{Submodels}

\subsubsection{Egg deposition, stock-recruitment, and} smolt production

An adult female's probability of spawning is dependent on the number of winters it has experienced after first sea migration, determined from Jensen et al. (2019) in the Halselva (Table 2). Fecundity, $E$, per spawning female is calculated as a function of body mass (a proxy for spawning energy), $M$ :

$$
\ln (E)=x_{s t a} \times \ln (M)+z_{s t a}
$$

where $x$ and $z$ are model parameters dependent on spawning stage sta (first-time spawner or repeat spawner), derived from data collected from wild Norwegian sea trout populations (Jonsson \& Jonsson 1999).

Recruitment ( $R$, number of smolts produced) is calculated from total egg deposition $(S$, stock, which is the sum of $E$ over all female spawning individuals) using a Beverton-Holt stock-recruitment model:

$$
R=\frac{(a \times S)}{(1+b \times S)}
$$

where $a$ and $b$ are model parameters:

$$
a=R_{\max } / S_{R 50}
$$


Table 2. Parameters of egg deposition, stock-recruitment, and smolt production

\begin{tabular}{|c|c|c|c|}
\hline Function & Symbol & Value & Description \\
\hline Spawning probability & $S p$ & $\left\{\begin{array}{l}0.070 N W=1 \\
0.100 N W=2 \\
0.571 N W=3 \\
0.935 N W=4 \\
0.988 N W=5 \\
0.999 N W=6 \\
1.000 N W \geq 7\end{array}\right\}$ & $\begin{array}{l}\text { Probability of an adult female spawning as a } \\
\text { function of number of winters after first sea } \\
\text { migration }(N W) \text { experienced }\end{array}$ \\
\hline Fecundity per spawning female & $\begin{array}{l}X \\
Z\end{array}$ & $\begin{array}{l}\left\{\begin{array}{l}0.800 \text { sta }=F T S \\
1.009 \text { sta }=R P\end{array}\right\} \\
\left\{\begin{array}{l}2.366 \text { sta }=F T S \\
0.695 \text { sta }=R P\end{array}\right\}\end{array}$ & $\begin{array}{l}\text { Parameters of egg production model for first-time } \\
\text { spawner }(F T S) \text { and repeat spawner }(R P) \text { stages (sta) }\end{array}$ \\
\hline Stock-recruitment curve & $\begin{array}{l}R_{\max } \\
S_{R 50}\end{array}$ & $\begin{array}{l}2750 \\
150000\end{array}$ & $\begin{array}{l}\text { Maximum smolt production } \\
\text { Stock size (eggs) where recruitment }=0.5 \times R_{\max }\end{array}$ \\
\hline Smolt age distribution & & $\left\{\begin{array}{r}1.2 A=2 \\
9.4 A=3 \\
32.1 A=4 \\
38.9 A=5 \\
15.5 A=6 \\
2.4 A=7 \\
0.3 A=8\end{array}\right\}$ & $\begin{array}{l}\text { Percentage of the smolts from a hatch cohort } \\
\text { smoltifying at a given age }(A) \text { in years after swim-up }\end{array}$ \\
\hline Smolt body mass distribution & & $\left\{\begin{array}{l}12.8 A=2 \\
26.8 A=3 \\
45.4 A=4 \\
57.6 A=5 \\
67.1 A=6 \\
80.0 A=7 \\
80.3 A=8\end{array}\right\}$ & $\begin{array}{l}\text { Body mass }(g) \text { of each smolt for a given age }(A) \text { in years } \\
\text { after swim-up }\end{array}$ \\
\hline
\end{tabular}

$$
b=1 / S_{R 50}
$$

where $R_{\max }$ is the maximum recruitment, and $S_{R 50}$ is the stock size at which the recruitment is $50 \%$ of $R_{\max }$. The model was parameterized based on estimates of egg and smolt production within the Halselva, with an $R_{\max }$ of 2750 smolts yr ${ }^{-1}$ (Table 2, Fig. 2A) that approximated the maximum sea trout smolt production measured in the Halselva (Jensen et al. 2016). However, we lacked sufficient data for robust determination of $S_{R 50}$, so this was parameterized subjectively as 150000 (baseline simulation). For most egg productions expected in this river, the egg to smolt survival rate would be $<1 \%$, even for a wide range of $S_{R 50}$ values (for example, from 50000 to 250000 ; see Fig. 2B). This survival rate is consistent with what has been established in sea trout populations of other rivers (see Section 4.1.2).
Smolt production from a given spawning year is distributed to occur across a range of years subsequent to the spawning year (Table 2), and smolts are assigned body masses according to age in years after swim-up from the spawning site after egg hatching, $A$, and assigned sex. Age-specific body masses (Table 2) were derived from Halselva length-at-age surveys (Jensen et al. 2012, 2015), using a condition factor $(K=0.787)$ to convert length-at-age into body mass-at-age. The sex distribution of smolts, $63 \%$ female and $37 \%$ male, was obtained from samples in the Halselva.

\subsubsection{Migration between river and sea}

The probability of a post-smolt individual migrating into the sea is parameterized to cumulative increase from 0 (Week 22 of the year and earlier) to 1 
A

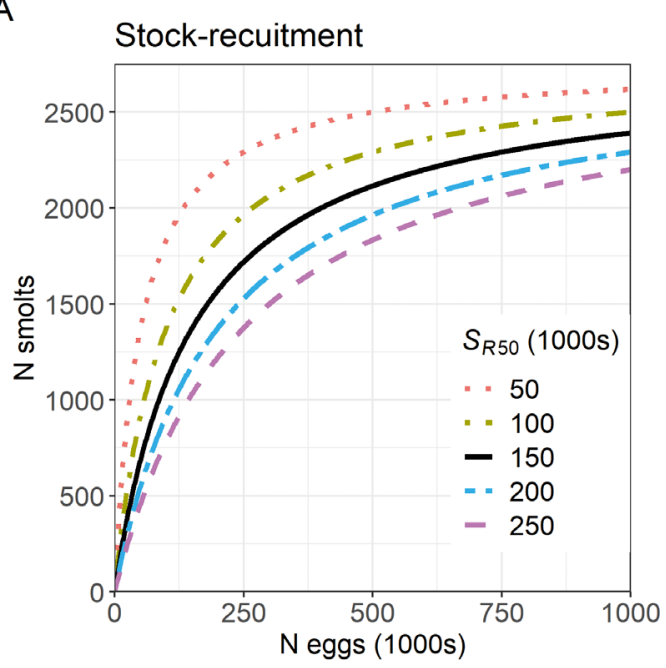

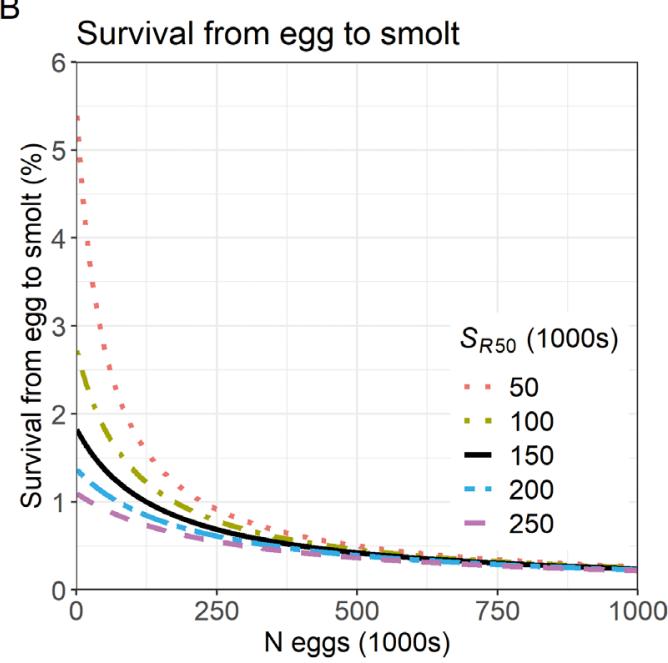

Fig. 2. (A) Stock-recruitment curve and (B) survival from egg to smolt for $R_{\max }=2750$. Continuous black line: the baseline parameterization of $S_{R 50}$

(Week 30). Veteran individuals in freshwater (those that have previously migrated to sea, and overwintered in freshwater) are parameterized to return to sea as function of week of the year earlier than postsmolt individuals, cumulatively increasing from 0 (Week 20 and earlier) to 1 (Week 25) (Table 3). These were parameterized to correspond to those empirically observed in the Halselva from a Carlin tagging program from 1988-2012 (see Jensen et al. 2012). The probability $(\mathrm{P})$ of a post-smolt or veteran individual returning to freshwater cumulatively increases with time since sea entry such that all sea trout return within 10 wk of being at sea: $\mathrm{P}($ return $)=0.1(6$ wk after entry), 0.2222 ( $7 \mathrm{wk}), 0.5714$ (8 wk), 0.6667 $(9 \mathrm{wk}), 1(10 \mathrm{wk})$. The mean time of return approximates that observed in the Halselva (Jensen et al. 2015).

\subsubsection{Background mortality}

Sea trout individuals at sea experience a weekly background mortality (summer marine mortality, $S M M$ ) that is independent of lice infestation levels, representing mortality from predation. This was parameterized to be a function of the number of summers at sea experienced, using estimates of survival at sea from outmigration to return acquired from the Halselva fish trap data (Jensen et al. 2019). Given that mortality is greatest during the first week at sea (see Aldvén \& Davidsen 2017), partly due to the energy cost of osmoregulatory adaptation, different weekly mortality probabilities were applied for the first week at sea and the subsequent weeks (Table 4).

For individuals that return to freshwater, an overwinter freshwater mortality (WFM) probability is applied on Week 52, dependent on the number of winters post-smoltification the sea trout has experienced, again parameterized using the fish trap data (Jensen et al. 2019).

\subsubsection{Body mass change}

For individuals at sea, body mass $M$ at time-step $(t+1)$ is estimated from body mass at time-step $t$ as:

$$
M_{t+1}=\left(\frac{\Omega \times t l \times 0.31}{100}+M_{t}^{0.31}\right) \frac{1}{0.31}
$$

Table 3. Probability (P) of a freshwater resident sea trout migrating to sea as a function of week of the year. NA: the function is not applied in that week (all sea trout have migrated to sea previously)

\begin{tabular}{|lcccccccccc|}
\hline Week & 21 & 22 & 23 & 24 & 25 & 26 & 27 & 28 & 29 & 30 \\
\hline P(smolt run) & 0 & 0 & 0.125 & 0.143 & 0.167 & 0.200 & 0.250 & 0.333 & 0.500 & 1.00 \\
P(veteran run) & 0.200 & 0.250 & 0.333 & 0.500 & 1.000 & NA & NA & NA & NA & NA \\
\hline
\end{tabular}


Table 4. Parameters of background mortality and body mass change

\begin{tabular}{|c|c|c|c|}
\hline Function & Symbol & Value & Description \\
\hline \multirow[t]{2}{*}{ Summer marine mortality } & \multirow[t]{2}{*}{$S M M$} & $\left\{\begin{array}{l}0.3605 N S=1 \\
0.2535 N S=2 \\
0.1310 N S \geq 3\end{array}\right\}$ & $\begin{array}{l}\text { Weekly mortality probability for first week at sea as a } \\
\text { function of number of summers (NS) experienced }\end{array}$ \\
\hline & & $\left\{\begin{array}{l}0.0880 N S=1 \\
0.0450 N S=2 \\
0.0179 N S \geq 3\end{array}\right\}$ & $\begin{array}{l}\text { Weekly mortality probability for subsequent weeks as a } \\
\text { function of NS experienced }\end{array}$ \\
\hline $\begin{array}{l}\text { Overwinter freshwater } \\
\text { mortality }\end{array}$ & $W F M$ & $\left\{\begin{array}{l}0.3767 N W=1 \\
0.2483 N W \geq 2\end{array}\right\}$ & $\begin{array}{l}\text { Total mortality probability while overwintering in } \\
\text { freshwater as a function of number of winters }(N W) \\
\text { experienced }\end{array}$ \\
\hline \multirow[t]{2}{*}{ Summer body mass increase } & $\Omega$ & $\left\{\begin{array}{r}7.19 N S=1 \\
10.33 N S=2 \\
10.23 N S=3 \\
9.72 N S \geq 4\end{array}\right\}$ & Standard specific growth rate \\
\hline & $t 1$ & 7 & Length of time-step (d) \\
\hline $\begin{array}{l}\text { Overwinter body mass } \\
\text { decrease }\end{array}$ & $W M D$ & $\left\{\begin{array}{l}12.2 \quad N W=1 \\
11.4 N W=2 \\
18.9 N W=3 \\
24.1 \quad N W=4 \\
24.0 N W \geq 5\end{array}\right\}$ & $\begin{array}{l}\text { Total decrease in body mass (\%) while overwintering in } \\
\text { freshwater }\end{array}$ \\
\hline
\end{tabular}

where $\Omega$ is the standard mass specific growth rate, which is dependent on the number of summers at sea experienced by the sea trout (Table 4 ; after A. J. Jensen unpubl. data) and $t l$ is the time-step length (d).

For individuals that have returned to freshwater, an overwinter body mass decrease is estimated as a percentage reduction (applied in Week 52), dependent on the number of winters post-smoltification the individual has experienced (Table 4; after A. J. Jensen unpubl. data).

\subsubsection{Lice infestation}

The number of additional lice attaching to each sea trout individual per week at sea is simulated from a negative binomial distribution, defined by the mean $\mu$ and dispersion parameter $\theta$ (Diserud et al. 2020), where $\theta=\mu / 8$. Mean lice infestation was set to peak in Week 35 (Fig. S1 in the Supplement at www.intres.com/articles/suppl/q013p145_supp.pdf), corresponding to that found in Altafjord. Lice attaching to the host are specified as being in the chalimus stage. Lice are specified as being in the preadult/adult stage after having been attached to the host individual for 2 wk, based on Hamre et al. (2013), who showed that preadults were observed on salmonid hosts 14-16 d after infestation (water temperature $\approx 10^{\circ} \mathrm{C}$ ).

\subsubsection{Lice-induced effects}

The probability of a lice-induced effect (LIE) per week of simulation on an infested host individual is determined from a sigmoid response curve based on the number of preadult/adult lice per gram of host body mass for each time-step:

$$
\mathrm{P}(L I E)=\frac{-1}{1+\exp (b / x-a)}+1
$$

where $x=$ number of preadult/adult lice $g^{-1}$ host body mass, and $a$ and $b$ are parameters determining the form of the equation: $a=(l o+h i) / 2$ and $b=2 /(l o-h i)$, where $l o$ and hi define the lower and upper inflexion points on the curve between which the slope is essentially linear. This was parameterized using the findings of Taranger et al. (2015), who reported data on mortality for 2 size groups $(<150 \mathrm{~g}$, and $>150 \mathrm{~g}$ salmonid post smolts) at different levels of lice infestation (number of lice $\mathrm{g}^{-1}$ host body mass). Different lice response curves are used for the different host size classes (Fig. 3): <150 g: lo =0.19, hi=0.30; $\geq 150 \mathrm{~g}: l o=$ $0.08, h i=0.1$. If the response curve initiates a liceinduced effect, 3 different types of effect are possible: (1) Lice-induced mortality. The individual dies and is discarded from further simulation.

(2) Lice-induced persistent premature return to freshwater. The individual adaptively responds to 
A

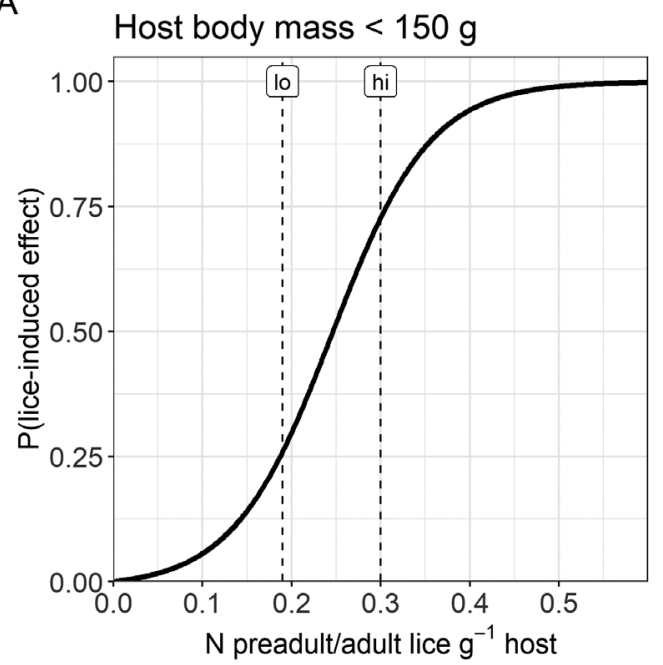

B

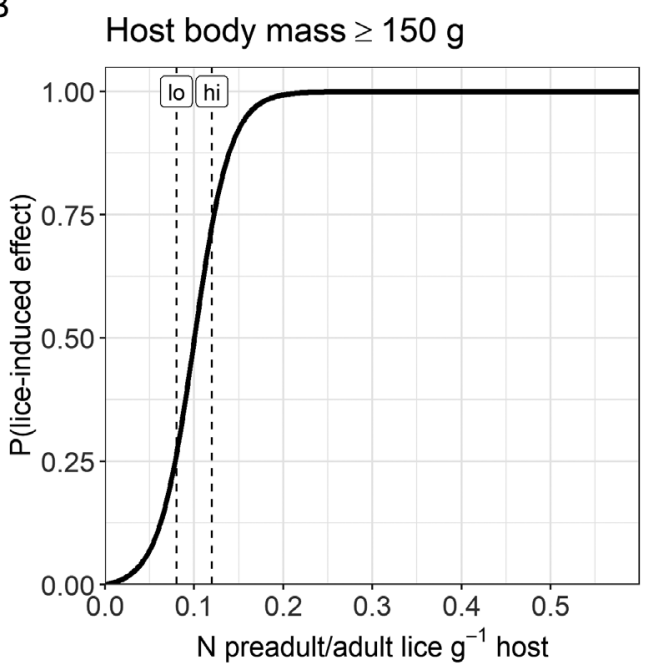

Fig. 3. Lice response curves (probability of a lice-induced effect as function of number of preadult/adult lice $\mathrm{g}^{-1}$ host body mass) for hosts with body mass (A) $<150 \mathrm{~g}$ and (B) $\geq 150 \mathrm{~g}$. In (A), lo=0.19 and $h i=0.30$; in (B), $l o=0.08$ and $h i=0.12$

lice infestation by returning to freshwater to delouse, where it remains until the following spring. It is not subject to potential further lice infestation until it returns to sea in the following spring.

(3) Lice-induced transitory premature return to freshwater. The individual adaptively responds to lice infestation by returning to freshwater to delouse, but it only remains there for the time-step it moves there and returns to sea in the following time-step. Transitory return lasts for only 1 time-step, on the assumption that the sea trout would stay in freshwater for as short a period as possible to allow for delousing but also to minimize energy costs associated with osmoregulatory adaptation (Finstad \& Ugedal 1998, Bronmark et al. 2014). This is consistent with the short transitory returns that have been reported, e.g. 7-46 d (Birkeland 1996). Background sea mortality is still applied, as it was assumed that predators would still be present in the brackish zone near the river mouth.

The probability of a lice-induced effect leading to one of these effect types (mortality, persistent return or transitory return) is specified according to simulation so that the effect on population abundance of each effect type may be investigated separately or together. For instance, to investigate how the sea trout population responds to lice-induced mortality alone, probabilities would be set as follows: $P$ (Lice-induced mortality) $=1$; P (Liceinduced persistent return $)=0 ; \mathrm{P}($ Lice- induced transitory return) $=0$. To investigate how the population responds to lice infestation where there is an equivalent probability of an effect leading to mortality or to persistent return, the probabilities would be: $\mathrm{P}$ (lice-induced mortality) $=0.5$; $\mathrm{P}$ (lice-induced persistent return $)=0.5$; $\mathrm{P}$ (lice-induced transitory return) $=0$.

\subsection{Simulation experiments}

To explore how lice infestation may affect sea trout population dynamics, 4 initial simulations were run (Table 5). The first (NoEff), with no effect of lice infestation applied, allowed a simulation of the population without lice effects and acted as a control simulation to compare effect types with. The other 3 showed how population dynamics might change according to the specific effect type that was present: either lice-induced mortality (Mort), lice-

Table 5. Simulations run to investigate the effect of different responses to lice infestation

\begin{tabular}{|lccc|}
\hline Simulation name & $\begin{array}{c}\text { Lice-induced } \\
\text { mortality }\end{array}$ & $\begin{array}{c}\text { Lice-induced } \\
\text { persistent pre- } \\
\text { mature return }\end{array}$ & $\begin{array}{c}\text { Lice-induced } \\
\text { transitory pre- } \\
\text { mature return }\end{array}$ \\
\hline NoEff & Absent & Absent & Absent \\
Mort & Present & Absent & Absent \\
Pret & Absent & Present & Absent \\
Tret & Absent & Absent & Present \\
Mort + Pret & Present & Present & Absent \\
Mort + Tret & Present & Absent & Present \\
\hline
\end{tabular}


induced persistent premature return (Pret) in which the sea trout would remain in freshwater until the following year, or lice-induced transitory premature return (Tret) in which the sea trout would return to sea the following week. Two further simulations were run to show the combined effects of having both lice-induced mortality and delousing behavior - either mortality alongside persistent premature return (Mort + Pret) or mortality alongside transitory premature return (Mort + Tret). In both these cases, if the response curve indicated an effect, the probability of a given effect type was set to be equivalent; e.g. for the Mort + Pret simulation, a lice-induced effect would lead to either mortality $(p=0.5)$ or to premature return $(\mathrm{p}=0.5)$.

The sensitivity of model predictions to the parameterization of lice effects was investigated by examining the number of returning adults under different lice infestation rates, lice response curves and lice response types. Firstly, values of the weekly mean infestation rate, $\mu$, were altered around the baseline value (Fig. S1) by a given percentage $(-50,-40, \ldots,+50)$ to determine the influence of infestation rates. Secondly, with the only potential effect of lice specified to be mortality, values of the lice response curve parameters ( $l o$ and hi) were altered by the given percentage around the baseline value, separately for the small size class $(<150 \mathrm{~g})$ and the large class $(\geq 150 \mathrm{~g})$. This enabled determination of how the shape of the lice response curve would affect the number of returners, assuming there was only lice-induced mortality and no premature return. Finally, given that there may be the potential for premature return (either persistent or transitory), simulations were run with a lice effect leading to either mortality or premature return (with the probability of an effect leading to premature return ranging from $0.0,0.1, \ldots 1.0$ ). This procedure was done separately for the 2 types of premature return (persistent and transitory).

The sensitivity of model predictions to the parameterization of the stock-recruitment curve was then determined by examining how the number of smolts produced depended upon $R_{\max }$ and $S_{R 50}$. Values of each parameter were sequentially altered by a given percentage $(-50,-40, \ldots,+50)$; when one parameter was altered, the other parameter value was kept as its baseline value (Table 2). Finally, to investigate the effect of the stock-recruitment parameterization relative to the effect of lice-induced mortality, this sensitivity analysis was repeated under conditions of lice-induced mortality (parameterized using baseline values).

\section{RESULTS}

\subsection{Lice prevalence and intensity trends}

The prevalence and infestation intensity of preadult/adult lice on fish at sea increased with time at sea from $2 \mathrm{wk}$ after first entry to sea (Week 23; infestation began in Week 21 but it took 2 wk for the lice to develop to the preadult/adult stage) (Fig. 4). The pattern of an increase in prevalence and intensity across the summer was consistent with that observed in Altafjord, but simulated levels were greater than those observed. For all simulations other than the simulation allowing for transitory premature return (Tret), prevalence reached $100 \%$ by Week 38 (Fig. 4A). Prevalence did not reach $100 \%$ when individuals responded to lice via transitory premature return because individuals moved to freshwater temporarily, deloused, and returned to sea as louse-free individuals. Mortality, persistent premature return or transitory premature return caused a reduction in mean lice intensity relative to the simulation where lice infestation had no effect due to the most heavily infested hosts dying or returning to freshwater (Fig. 4B). Lice intensity levels showed no long-term trends across the 100 simulated years (Fig. S2), reflecting the constant intra-annual pattern of infestation probability applied across the years.

\subsection{Sea trout abundance trends}

The intra-annual pattern simulated by the model showed an increase in sea-resident fish from Week 21 to Week $\approx 29$ (Fig. 5A), resulting from migration to sea of both post-smolts and veterans. The abundance of sea-resident fish declined from Week $\approx 30$ onwards due to both mortality at sea and the return of fish to freshwater. The simulation with lice-induced mortality resulted in lower weekly abundances throughout the summer when sea trout were at sea than the simulation with lice effects absent (Fig. 5B). Premature return resulted in reductions in sea trout abundance more towards the end of summer, where the percentage reduction in sea trout approached that of applying lice-induced mortality. Sea trout abundance showed no long-term trend across the 100 simulated years (Fig. S2), regardless of simulation conditions, indicating that effects of lice infestation were not great enough to cause population extirpation with the simulation parameters used.

Sea trout body mass increased with time spent at sea. Adult returners which returned prematurely had 

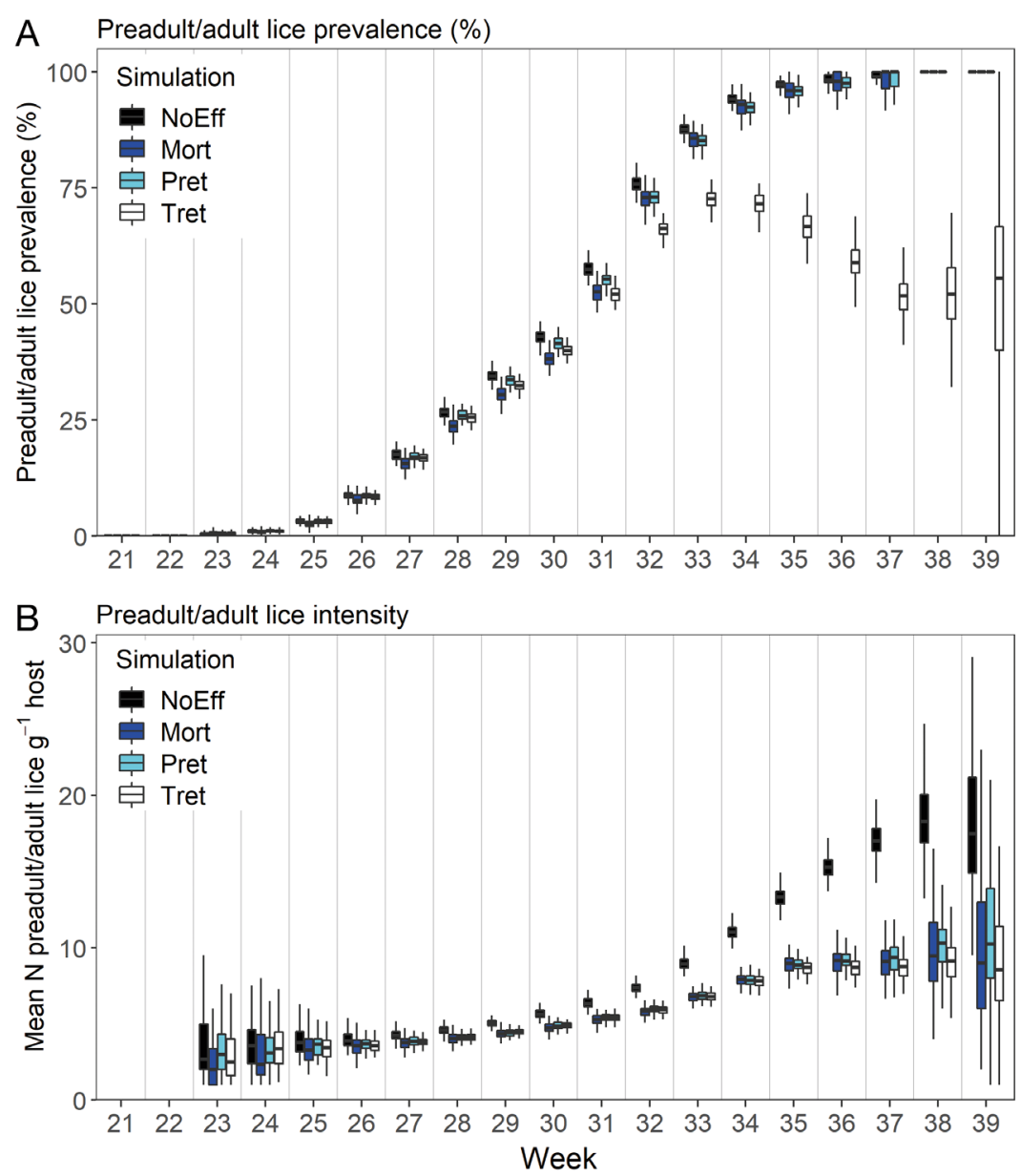

Fig. 4. Intra-annual pattern of (A) preadult/adult lice prevalence and (B) preadult/adult lice intensity (mean $\mathrm{N}$ preadult/adult lice $\mathrm{g}^{-1}$ host) of sea trout resident at sea for simulations with lice effects absent (NoEff), lice-induced mortality (Mort), lice-induced persistent premature return (Pret) and liceinduced transitory premature return (Tret). Individuals within freshwater (which all have zero lice) are excluded. Here and in Figs. 5 \& 6, boxplots are created from annual values for the given week. Here and in Figs 5-9, boxplots are centered around the median (horizontal lines), within the 25th and 75th percentiles (boxes), with whiskers extending to the largest value no further than $1.5 \times$ the interquartile range

spent less time at sea so consequently tended to have lower body mass than those which did not show this behavior (Fig. 6).

\subsection{Effect of lice on number of returners, body mass of returners, and total spawning female biomass}

The number of adult returners to freshwater was most strongly affected by parameterizing lice effects to only cause mortality (Fig. 7A), which resulted in $\mathrm{a} \approx 65 \%$ reduction in the number of returners relative to when not applying lice effects. This reduction was absent when the response to lice infesta- tion was parameterized to be persistent or transitory premature return. Numbers of returners were actually slightly greater when the simulation allowed only persistent premature return because this resulted in a shortening of the period at sea and thereby a reduction in total sea mortality. When both lice-induced mortality and lice-induced delousing behavior (either persistent or transitory premature return) were applied together, there was a $\approx 30 \%$ reduction in the number of adult returners.

The mean body mass of adults returning to freshwater strongly declined when lice effects were parameterized to be persistent premature return (Fig. 7B): fish that returned prematurely had had less time to grow at sea.

The net effect of lice infestation was determined by how it influenced the total spawning female biomass, which eventually determined the number of eggs deposited and therefore subsequent smolt production. Total spawning female biomass was dependent on both the number of returners and their individual body masses. The combined effect of changes in the numbers (Fig. 7A) and body masses (Fig. 7B) of returners was that total spawning female biomass was greatly reduced when lice-induced mortality was applied because fewer individuals returned (Fig. 7C). When only delousing responses were implemented - either persistent or transitory premature return - the total female biomass was maintained at a similar level to that where no effect of lice was applied. In the case of persistent return, body masses of returners were less, but the increased number of returners, due to reduced time and background mortality at sea, compensated for this.

\subsection{Sensitivity analysis}

Population abundance was highly sensitive to infestation rate, parameters of the lice response curve, and the type of response (mortality, persistent premature return or transitory premature re- 
A

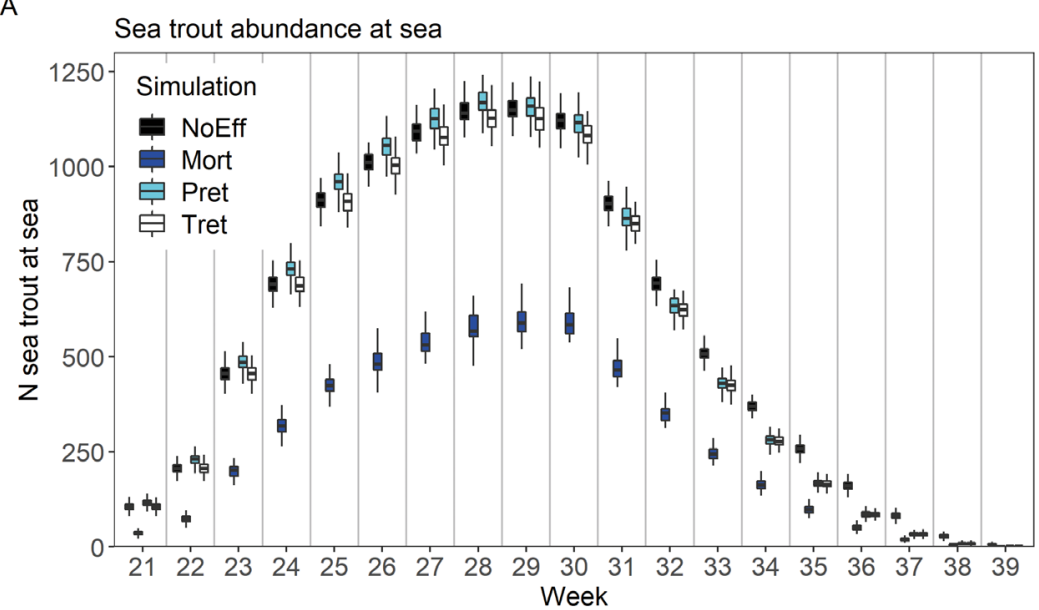

B

Fig. 5. Intra-annual pattern of (A) abundance of sea trout at sea for simulations with lice effects absent (NoEff), lice-induced mortality (Mort), lice-induced persistent premature return (Pret) and lice-induced transitory premature return (Tret), and (B) reduction (\%) in abundance from simulation with lice effects absent

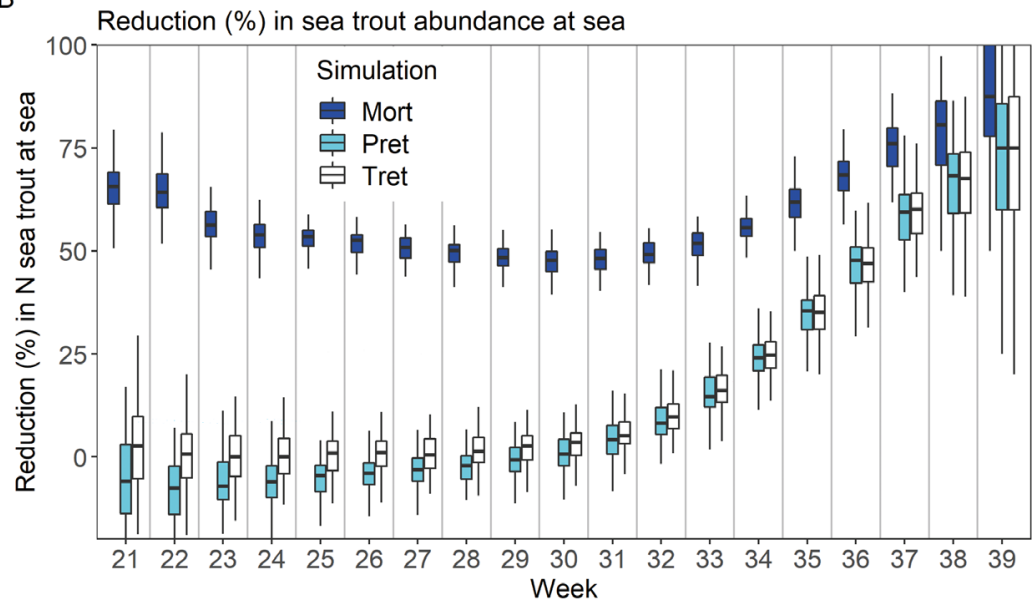

to cause premature return (either persistent or transitory) rather than mortality increased the number of returners. This was particularly the case for persistent rather than transitory premature return.

Population abundance was also affected by the parameterization of the stock-recruitment curve. Firstly, the number of smolts produced was positively related to $R_{\max }$ and negatively related to $S_{R 50}$ (Fig. 9A). A given percentage change in $R_{\max }$ from the baseline value had a greater effect on the number of returners than the equivalent percentage change in $S_{R 50}$. Secondly, the effect of the stock-recruitment curve parameterization was large relative to that of lice-induced mortality (Fig. 9B). Simulating under conditions of lice-induced mortality resulted in lower smolt production because there were fewer returners and less egg production. However, by increasing $R_{\max }$ or reducing $S_{R 50}$, it was possible to overcome the effect of lice-induced mortality. Additionally, the effect of lice-induced mortality was diminished at small $S_{R 50}$ values. For example, liceinduced mortality led to a $\approx 75 \%$ reduction in smolt production when $S_{R 50}$ was increased by $50 \%$ from its baseline value, but only a $\approx 15 \%$ reduction when $S_{R 50}$ was reduced by $50 \%$ from its baseline value.

\section{DISCUSSION}

tion was constrained to be lice-induced mortality, the number of returners was negatively related to the infestation rate, as a result of greater liceinduced mortality with higher infestation rates (Fig. 8A). The number of returners was more sensitive to the parameterization of the lice-induced response curve for large individuals ( $\geq 150 \mathrm{~g}$ ) than small individuals (<150 g) (Fig. 8B). For example, reducing $l o$ and hi parameter values for large individuals by $50 \%$ caused a $\approx 85 \%$ reduction in the number of returners, whereas reducing the same parameters for small individuals by the same amount only caused a $\approx 25 \%$ reduction in the number of returners. The type of response to lice infestation had a large effect on the number of returners (Fig. 8C). Increasing the probability of a lice effect
This study has shown that the manner in which sea trout respond to lice infestation strongly influences the overall effect on sea trout population abundance. Lice-induced mortality may result in large reductions in population abundance if the sea trout remain at sea for the whole summer. Delousing behavior, either through persistent or transitory premature return, may reduce this lice-induced mortality. In our modeling, persistent premature return also reduced background mortality through a shortening of the period at sea. Although persistent premature return results in smaller individuals returning, which have lower individual fecundity, the increased number of returners from this behavior may partly compensate for the 
A

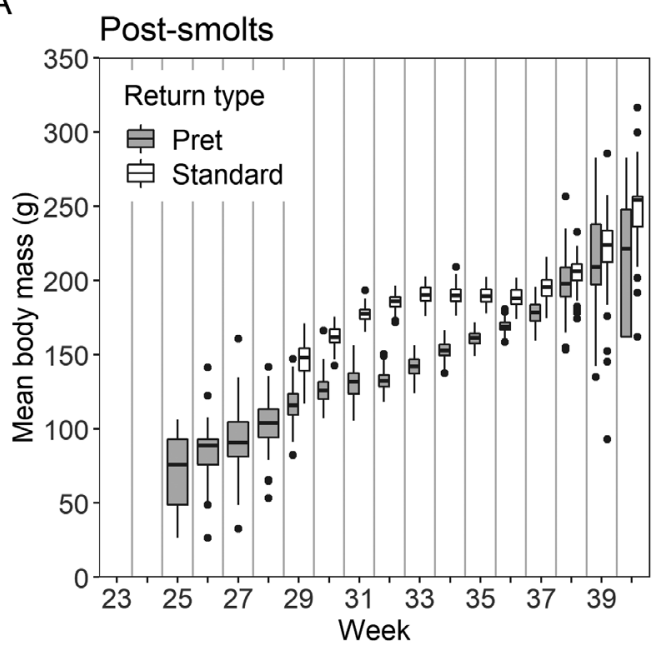

B

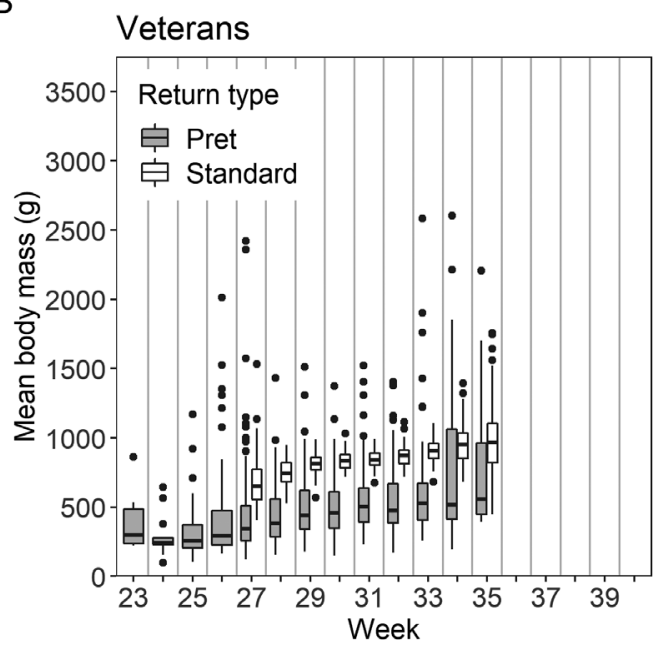

Fig. 6. Mean yearly body mass of returning (A) post-smolts and (B) veterans as a function of returning week for individuals returning after a standard time at sea (see Section 2.7.2) and individuals with persistent premature return (Pret)

reduction in growth. Thus, if a large proportion of the population shows this behavior instead of remaining at sea where they are at risk of lice-induced mortality, the negative effect on population abundance from lice infestation may be reduced.

The dynamic modeling approach used here enabled the evaluation of processes that are difficult to measure directly in nature, but its predictive ability depends on how well the model is formulated and function parameters are estimated. Next, we discuss issues with formulating a sea trout population dynamics model with respect to lice effects (Section 4.1) and suggest further developments for improved modeling (Section 4.2). We then address how this can be used to inform management decisions (Section 4.3).

\subsection{Formulating a sea trout population dynamics model}

Sea trout is a diverse and flexible species with alternative life history strategies, seasonal migration between radically different habitats, and options for compensatory behavior, making it a complicated
A

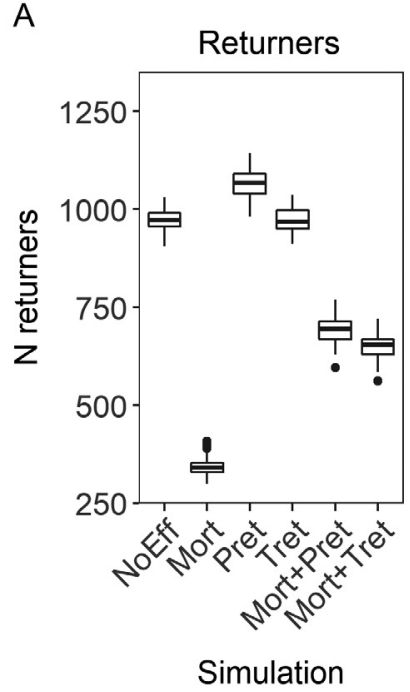

B

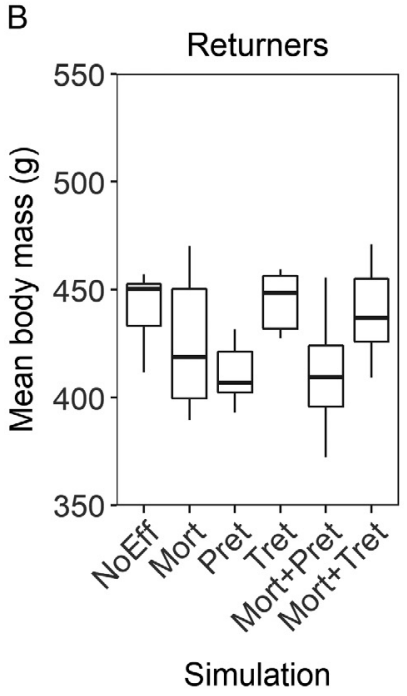

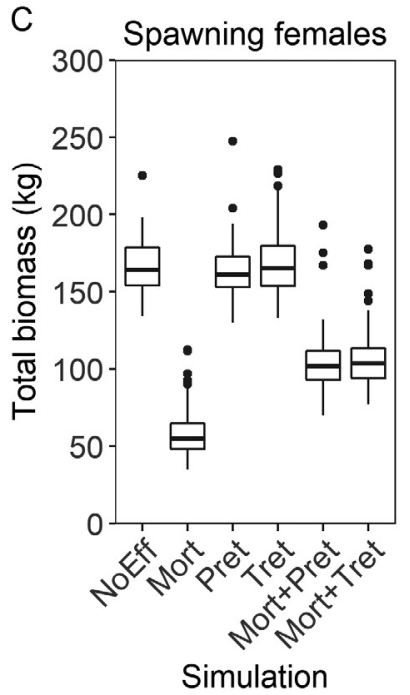

Fig. 7. (A) Number of returners, (B) mean body mass of returners and (C) total biomass of spawning females under conditions of no lice effects (NoEff), lice-induced mortality (Mort), lice-induced persistent premature return (Pret), lice-induced transitory premature return (Tret), lice-induced mortality plus persistent premature return (Mort + Pret), and lice-induced mortality plus transitory premature return (Mort + Tret). Here and in Figs 8 \& 9, boxplots are created from annual values 

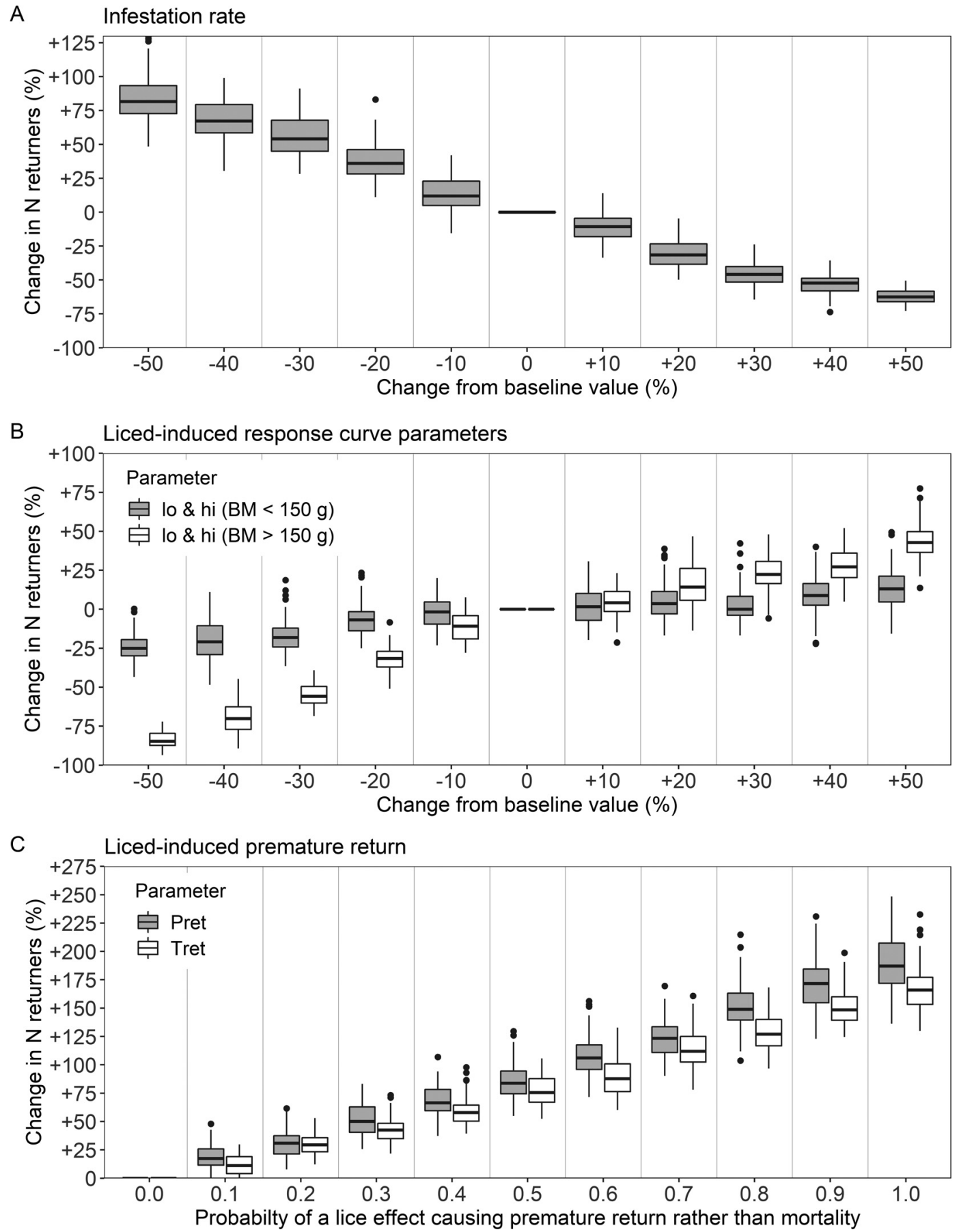

Fig. 8. Sensitivity of number of returners to (A) infestation rate, (B) parameters of lice-induced response curve and (C) type of response to lice infestation. In (B), lo and hi values have been changed separately for small (body mass $<150 \mathrm{~g}$ ) and large (body mass $\geq 150 \mathrm{~g}$ ) individuals. In $(\mathrm{C})$, the change in number of returners is expressed relative to the simulation where there is zero probability of a lice effect causing premature return and a probability of 1 that such an effect will cause mortality

species to model. Deterministic modeling allows examination of how sea trout populations can potentially be affected by salmon lice infestation, but it is necessary to be cognizant of model limitations in regards to what processes are included, how well these pro- cesses are parameterized, and how well simulations can be validated. Modeling a complex and stochastic host-parasite system necessitates some simplification, simply because data for model parameterization may be unavailable. We illustrate this issue below 

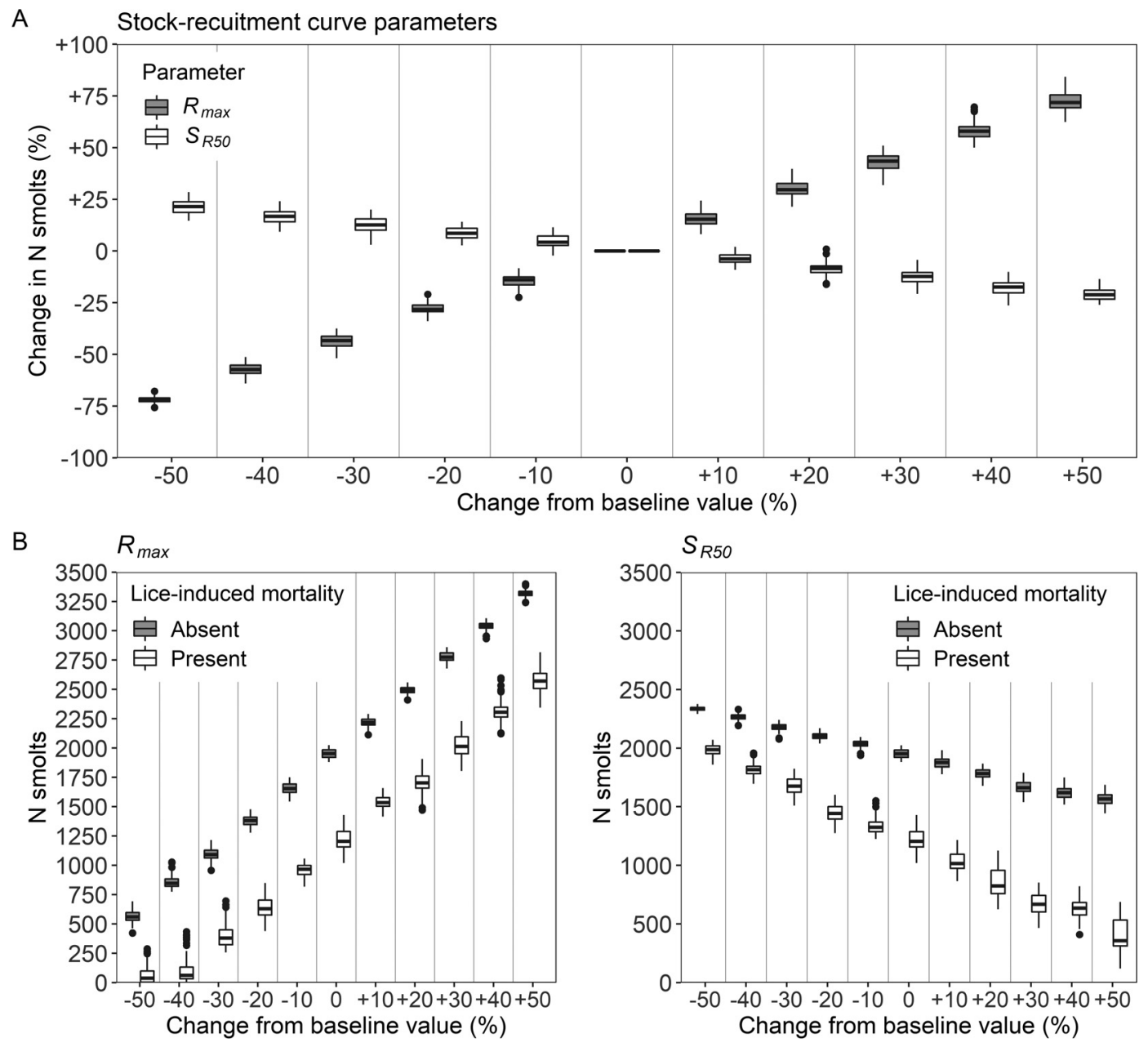

Fig. 9. Sensitivity of number of smolts to (A) parameters of stock-recruitment curve, and (B) parameters of stock-recruitment curve for conditions of lice-induced mortality being absent and present. In (A), simulations have been run under conditions of no lice-induced effects; in (B), no premature return was allowed

with regard to parameterizing lice effects and the stock-recruitment relationship.

\subsubsection{Parameterizing lice effects}

The lice-induced dose-response curve was parameterized based on empirical field studies. These studies were potentially influenced by uncontrolled factors which may have contributed to the wide variation in established thresholds for adverse effects from lice. We used the findings of Taranger et al. (2015) as a basis for parameterizing a sigmoid doseresponse curve, but their findings were only presented as thresholds, and other authors have reported different results (see Wagner et al. 2008), so the form of the response curve we used may have diverged from that existing in reality. Greater sensitiv- ity was found in this study regarding how the curve was parameterized for large individuals $(\geq 150 \mathrm{~g})$ compared to small individuals $(<150 \mathrm{~g})$. Most sea trout resident in the sea during summer were larger than $150 \mathrm{~g}$, so the abundance of these was more affected by the parameterization. However, there is the potential for markedly different results if a different size-dependency were used.

Likewise, the formulation of a delousing response was limited by the lack of detailed studies. We chose a short $1 \mathrm{wk}$ freshwater stay for transitory return on the assumption that sea trout would only stay there long enough to delouse, but reported lengths of delousing periods within rivers vary, and there is little information on lengths of delousing periods in brackish waters. Additional problems with the available data from existent field studies are that they were not collected with the purpose of calibrating determinis- 
tic models. For instance, there are multiple studies on premature return to freshwater and some studies on use of brackish zones for delousing (see Thorstad et al. 2015), but these studies tend to only report lice infestation on captured fish (i.e. only data on lice presence rather than on both presence and absence), making it difficult to formulate a model for delousing probability as a function of lice infestation. Model calibration has strong implications for predicted model dynamics, and environmental factors can modulate effects from lice on sea trout populations (Vollset 2019). Since populations may respond differently to lice infestation, the model must be calibrated to a range of different populations, habitats, and environmental conditions to illustrate the diversity of potential life-history trajectories.

\subsubsection{Parameterizing the stock-recruitment relationship}

The stock-recruitment relationship strongly affected how lice effects were manifested on smolt production, with the effects of lice-induced mortality on smolt production being reduced when $S_{R 50}$ was small. Lice-induced mortality at sea may reduce the number of eggs deposited, but if this reduction is occurring for stock levels expected to produce close to the maximum smolt production, the effect on production will be diminished. If the stock level falls below $S_{R 50}$, the gradient of this stock-recruitment relationship becomes large and the reduction in smolt production will be strong. There is therefore the potential for sustainable smolt production for a long time, followed by a dramatic fall if stock levels fall below this threshold. Stock-recruitment relationships for sea trout populations are often not well defined in comparison to Atlantic salmon populations, but are important for a population's resilience towards additional lice-induced mortality. In the current study, this relationship was parameterized based on available data within the Halselva, but these data were only available for relatively low egg deposition and smolt production rates, making setting the $S_{R 50}$ rather subjective. Sensitivity analysis showed simulated abundances to be sensitive to $S_{R 50}$, so improving estimates of $S_{R 50}$ deserves consideration. While egg to smolt survival rates were consistent with those found in the literature-e.g. 0.05-0.40 (Euzenat et al. 2006), 0.31, and 0.88\% (Rasmussen \& Pedersen 2006) — further information would improve the parameterization. Ongoing work by an ICES Working Group with the aim of developing assess- ment models and establishing biological reference points for sea trout populations (WGTRUTTA) (ICES 2018) is now beginning to establish stock-recruitment relationships for multiple populations around Europe, so it is likely that a better parameterization of the stock-recruitment relationship may be achieved in the future.

\subsection{Further developments}

Our model forms a scientific basis to examine the relative influence of lice-induced mortality, liceinduced return (either persistent or transitory), and the form of the stock-recruitment relationship on sea trout population abundance and dynamics. Model functions were developed to allow investigation of how they interact to control abundance and dynamics. The simulated environment and response was simple (for instance, no spatial variation in lice intensity, no adaptive or evolutionary response from the sea trout, and a simple, deterministic stock-recruitment relationship). There is scope for refinement of the functions to increase the model's ability to examine (1) indirect effects of lice infestation, (2) spatial patterns of lice infestation, and (3) uncertainties with regard to the nature of the stock-recruitment relationship.

A better parameterization of indirect effects of lice infestation, beyond the direct effects of lice-induced mortality and delousing behavior, would improve the ability for long-term prediction of effects on population structure and dynamics. Firstly, fecundity is affected by other factors than just female body size. A female that is large but that has not grown much during the previous summer may have low energy reserves for egg production. Lice-induced delayed female maturation and reduced spawning probability will also reduce the expected total lifetime egg production. Secondly, freshwater survival may be reduced if lice infestation is high, resulting from depleted energy reserves for overwintering and increased susceptibility to mortality due to the direct damage from lice. Finally, the sea trout population may become less anadromous if the lice burden is too great, reducing the expected spawning biomass in subsequent years. IBTRUTTA in its current form does not allow for adaptive responses to lice infestation. Models dealing with behavioral (Railsback \& Harvey 2017) or evolutionary (Ayllon et al. 2016) adaption within sea trout have been developed, so development of IBTRUTTA in these directions may allow for simulation of future changes in anadromy. Addressing the indirect effects of lice infestation on fecun- 
dity, winter survival, and non-anadromy may allow for a more accurate estimate of long-term population structure and dynamics, but requires further field studies for model calibration.

The current model setup involved a spatially integrated marine environment and ignored the potential for spatial patterns in infestation and sea trout response. Sea trout populations in different rivers and coastal regions are expected to respond differently to the same lice infestation pressure, caused by variation in available compensatory behavioral mechanisms and migration alternatives (Birnie-Gauvin et al. 2019). Spatial variation in marine habitat use among groups of fish within a population will affect the expected lice infestation, with consequent effects on population dynamics. Smolts may use different habitats to veteran migrants (Aldvén et al. 2015, Eldoy et al. 2015), and females and males may prioritize growth versus survival differently and choose different habitats (Thorstad et al. 2016). Infested sea trout may also move from areas with heavy infestation to find less-infested areas of the marine habitat (SerraLlinares et al. 2020) as a lice compensatory behavior. A more detailed modeling of spatial processes in the marine environment may be useful in studies where there are known gradients in infestation intensity arising from the placement of fish farms.

The stock-recruitment model applied in the current study may require further development when considering the compound effect of lice infestation and other factors within freshwater. In particular, further developments can be suggested in the area of (1) the strength of density regulation at different juvenile ages, (2) the effect of reduced anadromy in the trout population, (3) smolt age and size distributions, and (4) effects of environmental stochasticity (e.g. temperature and discharge). We used a simple deterministic stock-recruitment curve, but sensitivity analyses showed that lice-induced effects on population abundance were strongly dependent on parameters of the curve. However, established stock-recruitment curves sometimes show a weak relationship between stock and recruitment (see e.g. Euzenat et al. 2006). This may be associated with e.g. density-independent mortality occurring between the swim-up of fry from spawning sites and smoltification (Milner et al. 2003). The absence of a strong stock-recruitment relationship would mean that there would be no potential for mitigation or magnification of lice effects on the population via stock-recruitment. Potentially, implementation of a more stochastic stock-recruitment relationship, with model parameters varying temporally, may be use- ful to explore the uncertainty around stock-recruitment and how this may affect simulation results.

\subsection{Relevance for management of sea trout populations}

Sea trout populations occupy diverse environments with large natural stochasticity, have several alternative life history strategies, and are affected to varying extents by human activity. Data collection at critical life stages can be resource-demanding, and it may be impractical to base the management of populations solely on empirical data. Since many empirical studies focus on certain parts of the sea trout life history or aspects of lice infestation, there is a need for models that can compile this knowledge and evaluate the total accumulated adverse effects of lice infestation on sea trout populations. Dynamic models that can quantify the long-term impacts of direct and indirect effects of salmon lice infestation on sea trout population size and composition will be crucial for informing management decisions. Such a modeling approach may make it possible to predict the reduction in sea trout population size, growth at sea, and changes in size distribution and female lifetime reproductive potential as a consequence of increased lice infestation - useful information for incorporation in managements systems such as the Norwegian 'traffic light' system. Dynamic models are also suitable for illustrating how sea trout populations may respond to different future lice infestation scenarios, and for examining combined effects of lice infestation with other factors such as river regulation, pollution, and climate change.

This study has shown some of the complexity in how salmon lice infestation can affect sea trout populations. For example, delousing responses may partially ameliorate the effect of lice-induced mortality to sustain sea trout populations. However, to use such a model in a predictive capacity, with reasonable confidence in the validity of predictions, it is necessary to have a better parameterization of key functions using detailed data from the specific populations being modeled and to have a better understanding of the adverse effects of lice infestation on subsequent life-history traits.

Acknowledgements. This research was funded by the Norwegian Environment Agency (Miljødirektoratet, RN 20R27 F5D) and the Norwegian Institute for Nature Research (Strategic Institute Initiative 'Interactions between aquaculture and wild salmonids'). We acknowledge financial support from DNV GL. 


\section{LITERATURE CITED}

Aldvén D, Davidsen JG (2017) Marine migrations of sea trout (Salmo trutta). In: Proc Sea Trout: Science \& Management: Proc 2nd Int Sea Trout Symp. Troubador Publishing, Leicester, p 267-276

Aldvén D, Hedger RD, Økland F, Rivinoja P, Höjesjö J (2015) Migration speed, routes, and mortality rates of anadromous brown trout Salmo trutta during outward migration through a complex coastal habitat. Mar Ecol Prog Ser 541:151-163

Ayllon D, Railsback SF, Vincenzi S, Groeneveld J, Almodovar A, Grimm V (2016) InSTREAM-Gen: modelling ecoevolutionary dynamics of trout populations under anthropogenic environmental change. Ecol Modell 326: 36-53

Birkeland K (1996) Consequences of premature return by sea trout (Salmo trutta) infested with the salmon louse (Lepeophtheirus salmonis Kroyer): migration, growth, and mortality. Can J Fish Aquat Sci 53:2808-2813

Birkeland K, Jakobsen PJ (1997) Salmon lice, Lepeophtheirus salmonis, infestation as a causal agent of premature return to rivers and estuaries by sea trout, Salmo trutta, juveniles. Environ Biol Fishes 49:129-137

Birnie-Gauvin K, Thorstad EB, Aarestrup K (2019) Overlooked aspects of the Salmo salar and Salmo trutta lifecycles. Rev Fish Biol Fish 29:749-766

Bjørn PA, Finstad B (2002) Salmon lice, Lepeophtheirus salmonis (Kroyer), infestation in sympatric populations of Arctic char, Salvelinus alpinus (L.), and sea trout, Salmo trutta (L.), in areas near and distant from salmon farms. ICES J Mar Sci 59:131-139

Bronmark C, Hulthen K, Nilsson PA, Skov C, Hansson LA, Brodersen J, Chapman BB (2014) There and back again: migration in freshwater fishes. Can J Zool 92: $467-479$

* Diserud OH, Hedger RD, Finstad B, Hendrichsen D, Jensen AJ, Ugedal O (2020) Salmon louse infestation in wild brown trout populations generates multi-modal mixture distributions. Aquacult Environ Interact 12:447-456

Eldoy SH, Davidsen JG, Thorstad EB, Whoriskey F and others (2015) Marine migration and habitat use of anadromous brown trout (Salmo trutta). Can J Fish Aquat Sci 72:1366-1378

Euzenat G, Fournel F, Fagard JL (2006) Population dynamics and stock-recruitment relationship of sea trout in the River Bresle, Upper Normandy, France. In: Harris H, Milner N (eds) Sea trout: biology, conservation and management. Blackwell Publishing, Oxford p 307-326

Finstad B, Bjørn PA (2011) Present status and implications of salmon lice on wild salmonids in Norwegian coastal zones. In: Salmon lice: an integrated approach to understanding parasite abundance and distribution. WileyBlackwell, Oxford, p 281-305

Finstad B, Ugedal O (1998) Smolting of sea trout (Salmo trutta L.) in northern Norway. Aquaculture 168:341-349

Grimm V, Railsback SF, Vincenot CE, Berger U and others (2020) The ODD protocol for describing agent-based and other simulation models: a second update to improve clarity, replication, and structural realism. J Artif Soc Soc Simul 23:7

Halttunen E, Gjelland KØ, Hamel S, Serra-Llinares RM and others (2018) Sea trout adapt their migratory behaviour in response to high salmon lice concentrations. J Fish Dis 41:953-967
Hamre LA, Eichner C, Caipang CMA, Dalvin ST and others (2013) The salmon louse Lepeophtheirus salmonis (Copepoda: Caligidae) life cycle has only two chalimus stages. PLOS ONE 8:e73539

* Heuch PA, Mo TA (2001) A model of salmon louse production in Norway: effects of increasing salmon production and public management measures. Dis Aquat Org 45: $145-152$

ICES (2018) Interim report of the Working Group with the Aim to Develop Assessment Models and Establish Biological Reference Points for Sea Trout (Anadromous Salmo trutta) Populations (WGTRUTTA). ICES CM 2018/EPDSG:21. ICES, Copenhagen

Jensen AJ, Finstad B, Fiske P, Hvidsten NA, Rikardsen AH, Saksgård L (2012) Timing of smolt migration in sympatric populations of Atlantic salmon (Salmo salar), brown trout (Salmo trutta), and Arctic char (Salvelinus alpinus). Can J Fish Aquat Sci 69:711-723

Jensen AJ, Diserud OH, Finstad B, Fiske P, Rikardsen AH (2015) Between-watershed movements of two anadromous salmonids in the Arctic. Can J Fish Aquat Sci 72: 855-863

Jensen AJ, Finstad B, Fiske P, Saksgård L (2016) Smoltutvandring, marin vekst og sjøoverlevelse hos sjøørret, sjørøye og laks i Halselva, Finnmark. NINA Rapport 1238. Norsk institutt for naturforskning (NINA), Trondheim

Jensen AJ, Finstad B, Fiske P (2019) The cost of anadromy: marine and freshwater mortality rates in anadromous Arctic char and brown trout in the Arctic region of Norway. Can J Fish Aquat Sci 76:2408-2417

Konsson N, Jonsson B (1999) Trade-off between egg mass and egg number in brown trout. J Fish Biol 55:767-783

Karlsen Ø, Finstad B, Ugedal O, Svåsand T (2016) Kunnskapsstatus som grunnlag for kapasitetsjustering innen produksjons-områder basert på lakselus som indikator. Rapport fra Havforskningen, Book 14. Havforskningsinstituttet, Bergen

Lorenzen K (2008) Fish population regulation beyond 'stock and recruitment': the role of density-dependent growth in the recruited stock. Bull Mar Sci 83:181-196

Milner NJ, Elliott JM, Armstrong JD, Gardiner R, Welton JS, Ladle M (2003) The natural control of salmon and trout populations in streams. Fish Res 62:111-125

Nilsen R, Elvik K, Llinares R, Sandvik A and others (2018) Salmon lice infestation on wild salmonids along the Norwegian coastline in 2017. Rapport fra Havforskningen 42018. Havforskningsinstituttet, Bergen (in Norwegian)

R Development Core Team (2020) R: a language and environment for statistical computing. R Foundation for Statistical Computing, Vienna

Railsback SF, Harvey BC (2017) Understanding anadromy as an individual adaptive behaviour: theory and its consequences. In: Proc 2nd Int Sea Trout Symp. Troubadour Publishing, Leicester, p 41-52

Rasmussen GH, Pedersen S (2006) Sea trout (Salmo trutta L.) in Denmark. In: Harris H, Milner N (eds) Brown trout: biology, ecology and management. Troubadour Publishing, Leicester, p 483-522

* Serra-Llinares RM, Freitas C, Nilsen R, Elvik KMS and others (2018) Towards direct evidence of the effects of salmon lice (Lepeophtheirus salmonis Kroyer) on sea trout (Salmo trutta L.) in their natural habitat: proof of concept for a new combination of methods. Environ Biol Fishes 101:1677-1692 
Serra-Llinares R, Bøhn T, Karlsen Ø, Nilsen R and others (2020) Impacts of salmon lice on mortality, marine migration distance and premature return in sea trout. Mar Ecol Prog Ser 635:151-168

Skarðhamar J, Albretsen J, Sandvik AD, Lien VS and others (2018) Modelled salmon lice dispersion and infestation patterns in a sub-arctic fjord. ICES J Mar Sci 75:1733-1747

Taranger GL, Svåsand T, Kvamme BO, Kristiansen TS, Boxaspen KK (2013) Risk assessment of Norwegian aquaculture 2012. Fisken og Havet 2-2012. Havforskningsinstituttet, Bergen

Taranger GL, Karlsen Ø, Bannister RJ, Glover KA and others (2015) Risk assessment of the environmental impact of Norwegian Atlantic salmon farming. ICES J Mar Sci 72: 997-1021

Thorstad EB, Finstad B (2018) Impacts of salmon lice emanating from salmon farms on wild Atlantic salmon and sea trout. NINA Rep 1449. Norwegian Institute for Nature Research (NINA), Trondheim

Thorstad EB, Todd CD, Uglem I, Bjorn PA and others (2015) Effects of salmon lice Lepeophtheirus salmonis on wild sea trout Salmo trutta-a literature review. Aquacult Environ Interact 7:91-113

Thorstad EB, Todd CD, Uglem I, Bjorn PA and others (2016) Marine life of the sea trout. Mar Biol 163:47

Editorial responsibility: Tim Dempster,

Melbourne, Victoria, Australia

Reviewed by: 2 anonymous referees
Tully O, Poole WR, Whelan KF, Merigoux S (1993) Parameters and possible causes of epizootics of Lepeophtheirus salmonis (Kroyer) infesting sea trout (Salmo trutta L.) off the west coast of Ireland. In: Boxshall GA, Defaye D (eds) Pathogens of wild and farmed fish: sea lice. Ellis Horwood, Chichester, p 202-218

*Vollset KW (2019) Parasite induced mortality is context dependent in Atlantic salmon: insights from an individual-based model. Sci Rep 9:17377

*Vollset KW, Dohoo I, Karlsen O, Halttunen E and others (2018a) Disentangling the role of sea lice on the marine survival of Atlantic salmon. ICES J Mar Sci 75:50-60

Vollset KW, Qviller L, Skar B, Barlaup BT, Dohoo I (2018b) Parasitic sea louse infestations on wild sea trout: separating the roles of fish farms and temperature. Parasites Vectors 11:609

* Wagner GN, Fast MD, Johnson SC (2008) Physiology and immunology of Lepeophtheirus salmonis infections of salmonids. Trends Parasitol 24:176-183

Williams NE, O'Brien ML, Yao X (2017) Using survey data for agent-based modeling: design and challenges in a model of armed conflict and population change. In: Grow A, Van Bavel J (eds) Agent-based modelling in population studies: concepts, methods, and applications. Springer, Cham, p 159-184

Submitted: June 26, 2020;

Accepted: February 8, 2021

Proofs received from author(s): April 30, 2021 